\title{
Notch1 Is Required for Maintenance of the Reservoir of Adult Hippocampal Stem Cells
}

\author{
Jessica L. Ables, ${ }^{1}$ Nathan A. DeCarolis, ${ }^{1}$ Madeleine A. Johnson, ${ }^{1}$ Phillip D. Rivera, ${ }^{1}$ Zhengliang Gao, ${ }^{2}$ Don C. Cooper, ${ }^{3}$ \\ Freddy Radtke, ${ }^{4}$ Jenny Hsieh, ${ }^{2}$ and Amelia J. Eisch ${ }^{1}$ \\ Departments of ${ }^{1}$ Psychiatry and ${ }^{2}$ Molecular Biology, University of Texas Southwestern Medical Center, Dallas, Texas 75390, ${ }^{3}$ Institute for Behavioral \\ Genetics, University of Colorado at Boulder, Boulder, Colorado 80309, and ${ }^{4}$ Ecole Polytechnique Fédérale de Lausanne, Institut Suisse de Recherche \\ Experimentale sur le Cancer, 1066 Epalinges, Switzerland
}

Notch1 regulates neural stem cell (NSC) number during development, but its role in adult neurogenesis is unclear. We generated nestin-CreER ${ }^{\mathrm{T} 2} / \mathrm{R} 26 \mathrm{R}-\mathrm{YFP} /$ Notch $1{ }^{\text {loxP/loxP }}$ [Notchlinducible knock-out (iKO)] mice to allow tamoxifen (TAM)-inducible elimination of Notch1 and concomitant expression of yellow fluorescent protein (YFP) in nestin-expressing Type-1 NSCs and their progeny in the adult hippocampal subgranular zone (SGZ). Consistent with previous research, YFP+ cells in all stages of neurogenesis were evident in the subgranular zone (SGZ) of wild-type (WT) mice (nestin-CreER ${ }^{\mathrm{T} 2} / \mathrm{R} 26 \mathrm{R}-\mathrm{YFP} / \mathrm{Notch} 1^{\mathrm{w} / \mathrm{w}}$ ) after tamoxifen (post-TAM), producing adultgenerated YFP + dentate gyrus neurons. Compared with WT littermates, Notch1 iKO mice had similar numbers of total SGZ YFP + cells 13 and $30 \mathrm{~d}$ post-TAM but had significantly fewer SGZ YFP + cells 60 and $90 \mathrm{~d}$ post-TAM. Significantly fewer YFP+ Type-1 NSCs and transiently amplifying progenitors (TAPs) resulted in generation of fewer YFP + granule neurons in Notch $1 \mathrm{iKO}$ mice. Strikingly, $30 \mathrm{~d}$ of running rescued this deficit, as the total YFP + cell number in Notch iKO mice was equivalent to WT levels. This was even more notable given the persistent deficits in the Type-1 NSC and TAP reservoirs. Our data show that Notch1 signaling is required to maintain a reservoir of undifferentiated cells and ensure continuity of adult hippocampal neurogenesis, but that alternative Notch- and Type-1 NSCindependent pathways compensate in response to physical activity. These data shed light on the complex relationship between Type- 1 NSCs, adult neurogenesis, the neurogenic niche, and environmental stimuli.

\section{Introduction}

Neurogenesis occurs throughout adulthood in the subgranular zone (SGZ) of the mammalian dentate gyrus (Lagace et al., 2007; Imayoshi et al., 2008) and is linked with mood and hippocampal function (Doetsch and Hen, 2005; Ming and Song, 2005). Adult neurogenesis is dynamic and is thought to consist of a series of stages: proliferation of nestin-expressing neural stem cells

\footnotetext{
Received Sept. 8, 2009; revised Jan. 24, 2010; accepted May 24, 2010

This study was supported by National Institutes of Health (NIH)-National Institute on Drug Abuse grants to A.J.E. (DA023701, DA023555, DA016765); NIH T32 funds (T32 DA007290 and MH076690) that supported the training of N.A.D., M.A.J., and J.L.A.; and NIH individual training grant funds ( $\mathrm{F31}$ NS064632) to support the training of N.A.D. We are grateful to Drs. Diane Lagace, Scott Russo, Josh Breunig, Euiseok Kim, and to members of the Eisch laboratory for valuable discussion of this project and its results; Dr. Jane Johnson for mice; Dr. Eric Nestler for use of the confocal microscope in the Fishburg Department of Neuroscience at Mt. Sinai School of Medicine in NewYork; Kerstin Ure for dissections for neurospheres; and Allison Quast, Krishna Suri, Michael Robichaux, Ledo Bepo, and Amina Igeh for superb technical assistance. J.L.A. designed the study, performed breeding and treatment of animals, analyzed and documented the Notch elimination, running, colocalization of YFP with IHC markers, and performed the dendritic analysis and neurosphere experiments and wrote the paper. N.A.D. designed the study, established the parameters for and performed the immunohistochemistry for TAP, neuroblast, and immature neuron analysis and dendritic tracing studies, discussed the interpretations, and wrote the manuscript. M.A.J. analyzed and documented $A C 3+$ cells and wrote the paper. P.D.R. analyzed and documented colocalization of YFP/Ki67 and wrote the paper. Z.G. performed and documented the neurosphere experiments and wrote the paper. D.C.C. provided running wheels and wrote the paper. F.R. generated floxed Notch1 mice. J.H. supervised neurosphere experiments and wrote the paper A.J.E. designed and supervised the study, discussed results, formulated interpretations, and wrote the paper.

Correspondence should be addressed to Amelia J. Eisch, Department of Psychiatry, University of Texas Southwestern Medical Center, 5323 Harry Hines Boulevard, Dallas, TX 75390-9070. E-mail: amelia. eisch@utsouthwestern.edu.

DOI:10.1523/JNEUROSCI.4721-09.2010

Copyright $\odot 2010$ the authors $\quad 0270-6474 / 10 / 3010484-09 \$ 15.00 / 0$
}

(NSCs) and transiently amplifying progenitor cells (TAPs), maturation of doublecortin (DCX)-expressing neuroblasts, and survival of adult-born neurons that ultimately integrate into hippocampal circuitry (Kempermann et al., 2004; Duan et al., 2008). Each stage is discretely regulated by a variety of intrinsic and extrinsic factors, and modulation of adult SGZ neurogenesis by myriad stimuli (e.g., physical activity) is the focus of intense research (Eisch et al., 2008; Zhao et al., 2008). However, more information is needed about molecules that modulate the in vivo interaction between NSC, TAPs, and the neurogenic microenvironment-or "neurogenic niche" (Basak and Taylor, 2009).

Notch1 is a membrane-tethered transcription factor ideally situated to integrate cues from the niche to regulate various stages of neurogenesis (Artavanis-Tsakonas et al., 1999; Radtke et al., 2005; Yoon and Gaiano, 2005; Androutsellis-Theotokis et al., 2006; Johnson et al., 2009). In response to signals presented on the surface of neighboring cells, Notch1 governs self-renewal and fate in embryonic NSCs (Yoon and Gaiano, 2005; Corbin et al., 2008). Notch1 also promotes radial glia-like identity and negatively regulates cell cycle exit and neuronal differentiation in GFAP+ NSCs in the postnatal brain (Breunig et al., 2007; Favaro et al., 2009). However, the long-term consequences of impaired Notch1 signaling in nestin + Type-1 NSCs in the adult SGZ are unknown. Consistent with the idea that Notch signaling can also modulate neurogenesis in response to stimuli, recent studies suggest that ischemia-induced changes in neurogenesis are depen- 
dent on Notch1 (Carlén et al., 2009; Wang et al., 2009). A recent study using a Hes5-GFP reporter found that Notch-responsive stem cells respond differently to various stimuli (Lugert et al., 2010). However, there is no direct research into the causative links between Notch1, adult neurogenesis, and physical activity.

We hypothesized that Notch 1 signaling is critical for both basal and exercise-induced SGZ neurogenesis. To address this, we generated nestin-CreER ${ }^{\mathrm{T} 2} / \mathrm{R} 26 \mathrm{R}-\mathrm{YFP} /$ Notch 1 loxP/loxP [Notch1 inducible knock-out (iKO)] mice. Tamoxifen (TAM)induced recombination allowed us to ablate Notch 1 from nestinexpressing Type-1 NSCs and their progeny and to track the recombined cells via yellow fluorescent protein (YFP). We assessed YFP + cell number, proliferation, differentiation, and cell death in the SGZ of adult wild-type (WT) and Notch1 iKO mice over 3 months under both basal and running conditions. We find that Notch 1 is required for maintenance of adult hippocampal stem and progenitor cells and for continuity of adult neurogenesis. We further show that physical activity normalizes deficits in neurogenesis, despite persistent loss of NSCs.

\section{Materials and Methods}

Notch1 iKO mice. Mice were housed in an ALAAC-approved facility at UT Southwestern on a 12-h light/dark cycle. All procedures and husbandry were in accordance with the NIH Guide for the Care and Use of Laboratory Animals. Nestin-CreER ${ }^{\mathrm{T} 2}$ and R26R-YFP mice (Lagace et al., 2007) maintained on a C57BL/6J background were crossed with floxed Notch1 mice (Radtke et al., 1999), maintained on an ICR (CD1) background to generate viable and developmentally normal adult nestin$\mathrm{CreER}^{\mathrm{T} 2} / \mathrm{R} 26 \mathrm{R}-\mathrm{YFP} / \mathrm{Notch}^{\mathrm{w} / \mathrm{w}}$ (WT) and nestin-CreER ${ }^{\mathrm{T} 2} / \mathrm{R} 26 \mathrm{R}-\mathrm{YFP} /$ Notch $1^{\text {loxP/loxP }}$ (Notch iKO) littermates. Mice were genotyped as previously described (Radtke et al., 1999; Lagace et al., 2007). WT and Notch 1 iKO mice ( $4-5$ weeks old, male and female) received TAM daily for $6 \mathrm{~d}(180 \mathrm{mg} / \mathrm{kg}$ i.p., $30 \mathrm{mg} / \mathrm{ml}$ in 10\% EtOH/sunflower oil, SigmaAldrich). Only F3 intercross offspring were examined to control for gene dosage from the different backgrounds and to ensure that all littermates were heterozygous for both cre and $y f p$ and varied only for the floxed Notch1 allele (appropriate Mendelian ratios were observed). This was important given that running activity and neurogenesis are both highly strain dependent (Kempermann et al., 2006; Pietropaolo et al., 2008; Bednarczyk et al., 2009), and to minimize Cre and/or YFP-mediated toxicity (Imayoshi et al., 2006).

Voluntary physical activity. Mice were single-housed in modified cages with a locked (unable to turn) or open running wheel (Coulbourn Instruments). Revolutions were monitored, and activity was analyzed using ClockLab (ActiMetrics software). There was no statistical difference between any measures from mice on a locked wheel (cage dimensions $=$ $13 \times 31.8 \times 13.7 \mathrm{~cm})$ and naive group-housed mice $(12.7 \times 28.3 \times 17.5$ $\mathrm{cm})$, so data from these nonrunner groups were combined and compared with the running group.

Tissue preparation and immunohistochemistry. Mice were killed and perfused 13,30, 60, or $90 \mathrm{~d}$ after the last TAM injection, and brain sections were prepared as previously described (Donovan et al., 2006; Lagace et al., 2007). Staining was performed slide-mounted (SM) or free-floating (FF) (Lagace et al., 2007; Donovan et al., 2008) using the following primary antibodies: rabbit polyclonal anti-GFP (1:3000 SM; Invitrogen, catalog \#A11122), chicken polyclonal anti-GFP (1:500 SM, 1:100,000 FF, Aves Labs, catalog \#GFP-1020), rabbit monoclonal antiKi67 (1:500 SM, Lab Vision/NeoMarkers, Thermo Fisher Scientific, catalog \#RM-9106-S), rabbit polyclonal anti-cleaved caspase-3 (AC3, 1:500 SM, Cell Signal, catalog \#9661), goat polyclonal anti-DCX (1:100 SM, 1:5000 FF; Santa Cruz Biotechnology, catalog \#sc-8066), rabbit antiS100 $\beta$ (1:2000 FF, Swant, catalog \#37-a), mouse anti-GFAP (1:2500 FF, Millipore, catalog \#MAB360), mouse anti-NeuN (1:1000 FF, Millipore, catalog \#MAB377).

For SM IHC, sections were mounted on slides and incubated in $0.01 \mathrm{M}$ citric acid $\left(\mathrm{pH} 6.0,100^{\circ} \mathrm{C}\right)$ for $15 \mathrm{~min}$ for antigen retrieval. For AC3 additional permeabilization in $0.1 \%$ trypsin in $0.1 \% \mathrm{CaCl}_{2}$ in $0.1 \mathrm{M}$ Tris for $10 \mathrm{~min}$ was followed by $2 \mathrm{~N} \mathrm{HCl}$ in $1 \times \mathrm{TBS}$ for $30 \mathrm{~min}$. Slides were incubated with blocking solution (3\% normal donkey serum, $0.3 \%$ Triton $\mathrm{X}-100$ in $1 \times \mathrm{TBS}$ ) for $\geq 20 \mathrm{~min}$ followed by primary antibodies in carrier (3\% normal donkey serum, $0.3 \%$ Tween 20 in $1 \times$ TBS) overnight at RT. Antibody staining for DCX, Ki67, AC3, and chicken anti-GFP was revealed using species-specific fluorophore-conjugated secondary antibodies (1:200 in 1× TBS, Cy2, Cy3, and Cy5, Jackson ImmunoResearch). For quantification and morphological assessment of YFP + cells, slides were stained with rabbit anti-GFP and detected with biotinylated secondary antibody (1:200 in 1× TBS, Jackson ImmunoResearch), amplified using ABC Elite kit (Vector Laboratories, catalog \#PK-6100) and revealed with TSA Renaissance fluorescent amplification kit (1:50, PerkinElmer Life Sciences, catalog \#NEL701). Endogenous peroxidase activity was quenched in $0.3 \% \mathrm{H}_{2} \mathrm{O}_{2}$ for 30 min before $\mathrm{ABC}$ and TSA. All sections were counterstained with DAPI (1:5000, Roche Applied Science, catalog \#236276) before they were dehydrated and coverslipped with DPX (Sigma-Aldrich, catalog \#44581). Omission of primary or secondary antibodies resulted in no staining and served as a negative control.

For FF IHC to assess colocalization of YFP/S100 $\beta /$ GFAP or YFP/DCX/ NeuN, YFP was identified with chicken anti-GFP first, followed by staining for the other antigens. For staining of chicken anti-GFP followed by goat anti-DCX, sections incubated in modified blocking solution (3\% normal donkey serum, $0.3 \%$ Triton X-100, 2\% ABC Elite kit reagent A in $1 \times$ TBS) for $\geq 20 \mathrm{~min}$, followed by primary antibodies in modified carrier (3\% normal donkey serum, $0.3 \%$ Tween 20, 2\% ABC Elite kit reagent $\mathrm{B}$ in $1 \times$ TBS) overnight at RT. Sections were incubated in $1 \% \mathrm{H}_{2} \mathrm{O}_{2}$ for $30 \mathrm{~min}$, washed $4 \times 5 \mathrm{~min}$ in $1 \times \mathrm{TBS}$, then incubated with biotinylated secondary antibody (1:200 in 1.5\% normal donkey serum in $1 \times \mathrm{TBS})$ for $4-6 \mathrm{~h}$ at RT, washed, amplified for $1 \mathrm{~h}$ using ABC Elite kit, washed $4 \times 10$ min, and revealed for 12 min with TSA Renaissance fluorescent amplification kit. Antibody staining for NeuN, GFAP, and S100 $\beta$ was revealed using species-specific fluorophore-conjugated secondary antibodies (1: 200 in $1.5 \%$ normal donkey serum in $1 \times$ TBS) for $4-6 \mathrm{~h}$ at RT. After all staining was complete, sections were counterstained with DAPI for 20 min, washed, mounted onto uncharged slides and coverslipped with DPX.

Analysis of immunoreactive cells. Quantification was performed with an Olympus BX-51 microscope $(400 \times)$ as previously described (Mandyam et al., 2004; Donovan et al., 2006; Lagace et al., 2007, 2008, 2010). Briefly, an observer blind to experimental groups counted immunoreactive cells in the SGZ in every ninth coronal section throughout the dentate gyrus $(-0.82 \mathrm{~mm}$ to $-4.24 \mathrm{~mm}$ from bregma) via the optical fractionator method. Quantification of YFP + SGZ cells and YFP+ SGZ cells with Type-1 NSC or neuronal morphology was performed similarly via the optical fractionator method by an observer blind to experimental group. The proportion of YFP+ Type-1 NSC or YFP + neurons was determined by dividing the number of YFP + cells with either morphology by the total number of YFP+ cells (Donovan et al., 2008; Imayoshi et al., 2008). For phenotypic and dendritic morphology analyses, colocalization of signals was determined by scanning and optical sectioning in the $\mathrm{Z}$ plane of triple-immunofluorescence labeled sections with a Zeiss Axiovert 200/LSM510 confocal microscope (emission wavelengths 488, 543 , and $633,630 \times$ ). For phenotyping, 100-150 YFP + cells per animal ( $n \geq 3$ per group) were analyzed and the total number of YFP + cells immunoreactive for Ki67 or DCX was calculated by multiplying total $\mathrm{YFP}+$ counts by the proportion that expressed the marker for each animal. For dendritic analysis, Z-stacks of DCX + YFP + cells with a process extending through the GCL were imported into Neurolucida (Version 8, MicroBrightField) to obtain two-dimensional tracings of neurons (3-15 cells/animal, $n=3$ per group), followed by Sholl analysis (Breunig et al., 2007; Dahlhaus et al., 2008). Statistical significance was generally determined by one- or two-way ANOVA, followed by Bonferroni post hoc, and detailed statistics are provided in Table 2 (see below) and supplemental Table 1 (available at www.jneurosci.org as supplemental material).

Neurosphere isolation. Neurospheres were isolated from the subventricular zone as previously described (Brewer and Torricelli, 2007) from mice $40 \mathrm{~d}$ post-TAM. Briefly, dissections from two WT or Notch1 iKO mice were pooled and dissociated enzymatically for $40 \mathrm{~min}$ at $37^{\circ} \mathrm{C}$ and plated at equal density $(10$ cells/ $\mu \mathrm{l})$. Neurospheres were maintained in 


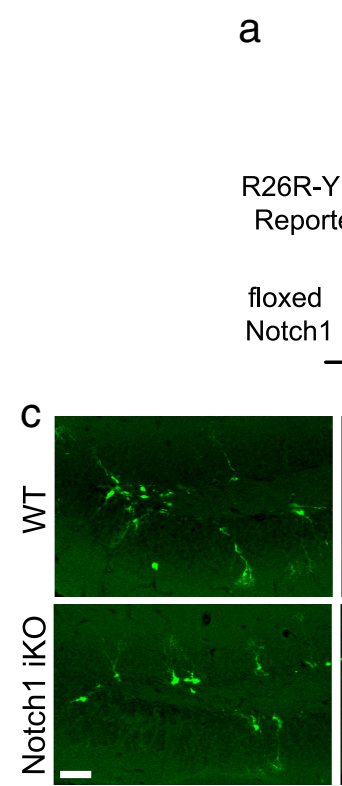

13
Nestin-CreER ${ }^{\mathrm{T} 2}$
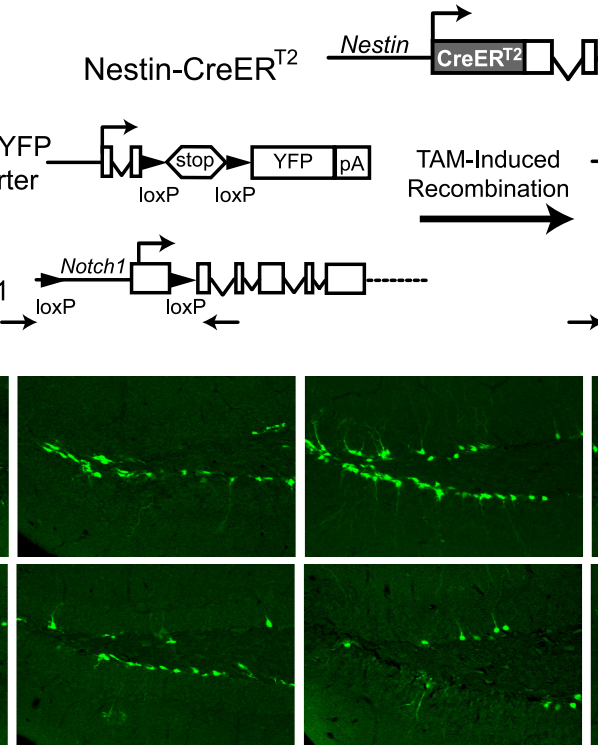

30

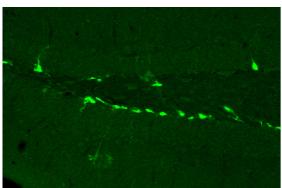

Days post-TAM
60
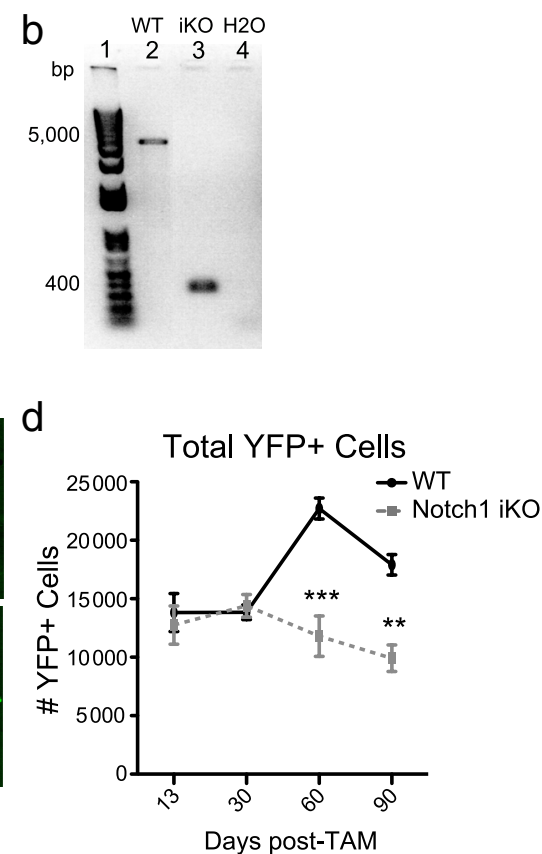

Figure 1. Notch1 iKO mice have fewer YFP + cells in the SGZ. $\boldsymbol{a}$, Nestin-CreER ${ }^{\mathrm{T}}$ and R26R-YFP mice were crossed with floxed Notch1 mice to generate Notch $1 \mathrm{iKO}$ mice. A large portion of the rat nestin gene drives expression of a fusion protein of (re recombinase and the modified estrogen receptor (CreER ${ }^{\text {T2}}$ ). Administration of tamoxifen (TAM) results in removal of the promoter and first exon of notch1, and the "stop" signal of R26R-YFP. This leads to elimination of Notch1 and to expression of YFP in nestin-expressing cells and their progeny. $\boldsymbol{b}$, PCR of neurospheres isolated 40d post-TAM confirmed that the notch 1 locus was recombined after TAM in Notch $1 \mathrm{iK} 0$ mice but not WT littermates. Primers (indicated by arrows in $\boldsymbol{a}$ ) were designed against regions outside the floxed portion of notch1. c, YFP + SGZ cells in WT and Notch1 iKO mice. d, YFP + SGZ cell number. ${ }^{* *} p<0.01$, ${ }^{* * *} p<0.001$ vs WT, Bonferroni post hoc; $n=5-11 /$ group. Scale bar: (c), $50 \mu \mathrm{m}$.

serum-free culture media supplemented with N2, B27, bFGF, EGF and heparin and passaged when confluent (every 7-10 d) using trypsinEDTA. Secondary spheres were counted at confluence ( $7 \mathrm{~d}$ after plating) using a $1 \mathrm{~mm}$ gridded dish. Genomic DNA was isolated from passage 4 neurospheres and PCR confirmed genomic recombination using the forward primer $5^{\prime}$-ctg act tag tag ggg gaa aac and the reverse primer: $5^{\prime}$-tac tcc gac acc caa tac ct.

\section{Results}

\section{Generation of Notch1 iKO mice}

To target disruption of Notch1 signaling to nestin-expressing cells in the adult hippocampus, we generated Notch1 iKO mice. TAM administration induced expression of YFP in WT and iKO mice, as well as elimination of the promoter and first exon of notch1 from nestin-expressing progenitors in iKO mice (Fig. $1 a, b)$. YFP + cells presented morphologies and phenotypes consistent with the stages of SGZ neurogenesis. YFP+ astrocytes $(\mathrm{S} 100 \beta+)$ and oligodendrocytes were extremely rare in the dentate gyrus, consistent with our previous finding that progeny of nestin-expressing cells in the SGZ are primarily neurons (Lagace et al., 2007).

\section{Adult Notch1 iKO mice have fewer SGZ YFP+ cells}

To determine the effect of Notch1 ablation from nestinexpressing Type-1 NSCs and their progeny on adult SGZ neurogenesis, we assessed the number of YFP + cells in WT and Notch1 iKO mice. Qualitatively, Notch1 iKO mice had fewer YFP + cells 60 and $90 \mathrm{~d}$ post-TAM (Fig. 1c). Quantitative assessment confirmed that the number of YFP + cells increased over time in WT mice, as previously shown (Lagace et al., 2007), but not in Notch1 iKO mice (Fig. 1d), suggesting that Notch1 is necessary for continuous generation of adult SGZ cells.

\section{YFP+ SGZ Type-1 NSCs and TAPs are reduced in Notch1 iKO mice}

To assess which neurogenic stages were affected by elimination of Notch1 from nestin-expressing cells, YFP+ SGZ cells were assigned to categories based on expression of IHC markers (Fig. $2 a$, Table 1) (Kempermann et al., 2004). YFP+ TAPs (Ki67+DCX-), proliferating neuroblasts $(\mathrm{Ki} 67+\mathrm{DCX}+)$, and postmitotic immature neurons $(\mathrm{Ki} 67-\mathrm{DCX}+)$ were evident in both WT and iKO mice. YFP + Type-1 NSCs (Fig. 2b) and mature neurons (Fig. 2d) were identified based on their distinctive morphology as previously reported (Lagace et al., 2007). Similar results were obtained using morphological criteria or phenotypic markers (supplemental Fig. 1 $a-f$, available at www.jneurosci.org as supplemental material). At early times post-TAM, there were no differences between WT and KO mice in the number of YFP+ cells or their phenotypic distribution. While the number of YFP+ Type-1 NSCs remained constant in WT mice, the number of labeled NSCs decreased significantly $\geq 60 \mathrm{~d}$ post-TAM in iKO littermates (Fig. $2 e$ ), which was confirmed via quantification of $\mathrm{YFP}+\mathrm{GFAP}+\mathrm{S} 100 \beta-$ NSCs (supplemental Fig. $1 a-c$, available at www.jneurosci.org as supplemental material). Notch1 iKO mice had fewer TAPs than WT mice (Fig. $2 f$ ), and $\geq 60$ d post-TAM there were significantly fewer YFP + neuroblasts (Fig. $2 g$ ), immature neurons (Fig. $2 h$ ), and mature neurons (Fig. $2 i$ ) in iKO mice, the latter result confirmed via quantification of $\mathrm{YFP}+\mathrm{NeuN}+$ neurons (supplemental Fig. $1 d-f$, available at www.jneurosci.org as supplemental material). Intriguingly, while we found a significant difference in the number of YFP + cells generated in Notch iKO mice compared with their WT littermates (Table 2), we found no differences in the proportion of cell types generated (supplemental Fig. $1 g-k$, supplemental Table 1, available at www.jneurosci.org as supplemental material), suggesting that fate of YFP + cells is not 
a
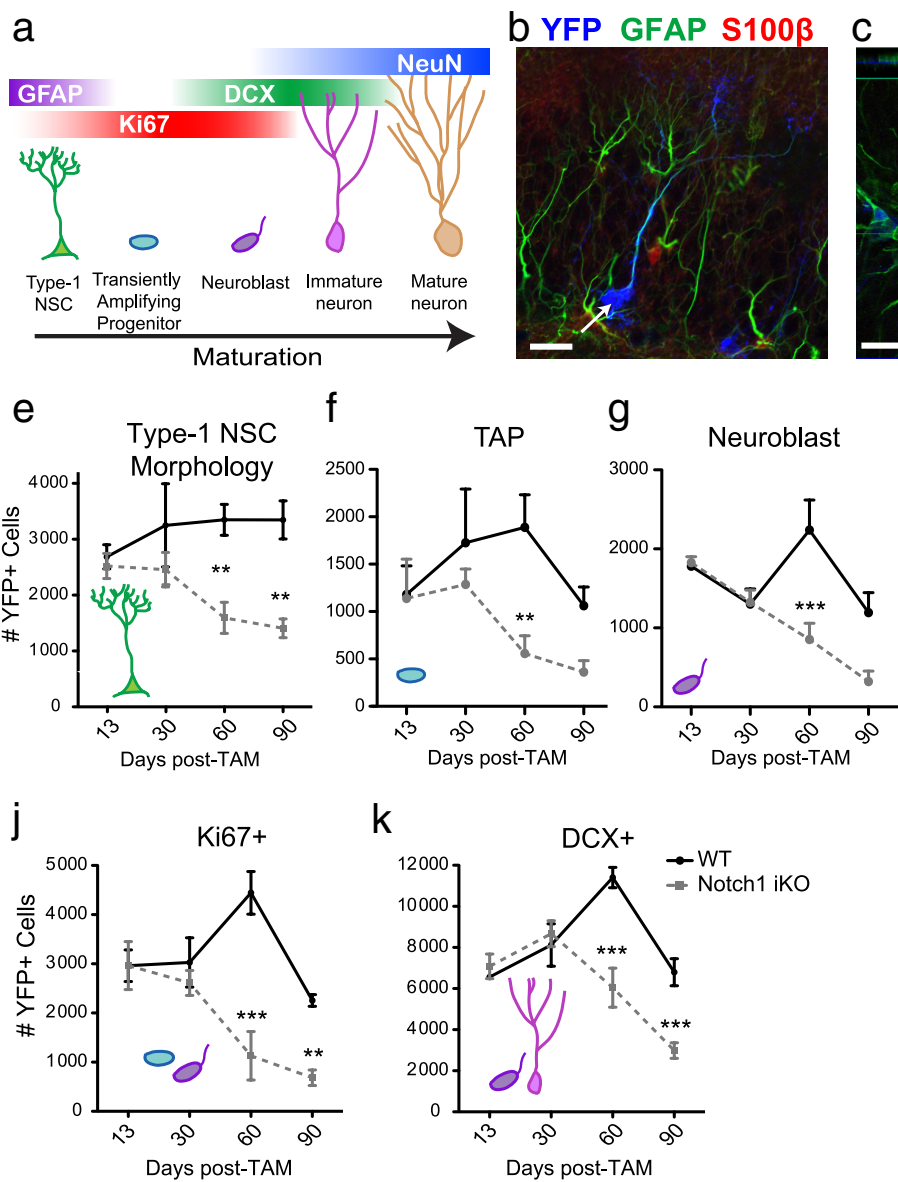

k

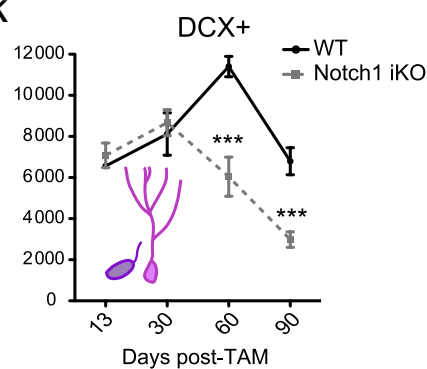

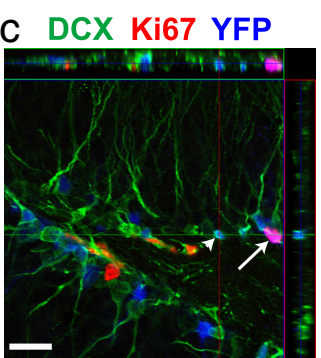

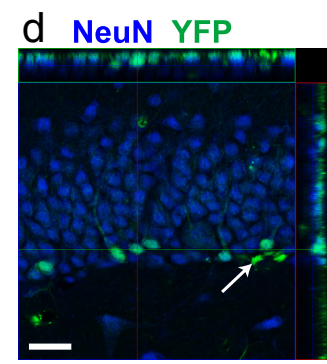

h

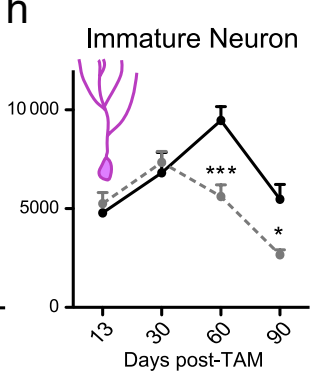

i
I

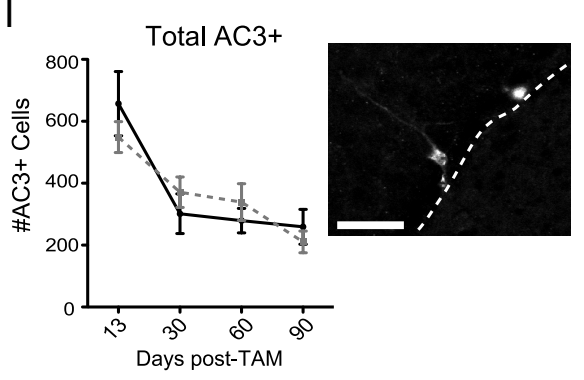

Figure 2. Elimination of Notch1 from nestin-expressing cells decreases YFP + SGZ NSC number and neurogenesis. $\boldsymbol{a}$, YFP + SGZ cells express markers across stages of neurogenesis. $\boldsymbol{b}$, YFP + GFAP + S100 $\beta$ - Type-1 NSC (arrow). c, YFP + Ki67 + DCX - (arrow) and YFP + Ki67 - DCX + (arrowhead) cells. d, YFP + NeuN + neurons (YFP + NeuN - cell, arrow).e, Notch1 iK0 mice have significantly fewer Type-1 NSCs at extended times post-TAM. $\boldsymbol{f}$, There are fewer TAPs (YFP+Ki67+DCX - cells) in Notch1 iK0 mice regardless of time post-TAM. $\boldsymbol{g}$, Notch1 iK0 mice have significantly fewer neuroblasts (YFP + Ki67+DCX+ cells) at $60 \mathrm{~d}$ post-TAM. $\boldsymbol{h}$, Notch1 iK0 mice have significantly fewer immature neurons (YFP + Ki67 - DCX + cells) at extended times post-TAM. $\boldsymbol{i}$, Notch1 iKO mice have significantly fewer YFP + neurons at extended times post-TAM. $\boldsymbol{j}$, Notch1 iKO mice have significantly fewer proliferating (Ki67 + ) YFP + cells at extended times post-TAM. $\boldsymbol{k}$, The number of YFP + cells that are becoming neurons (DCX+ ) is significantly decreased in Notch 1 iKO mice at extended times post-TAM. $I$, Apoptosis is not increased in the SGZ of Notch 1 iKO mice compared with WT littermates. ${ }^{*} p<0.05,{ }^{* *} p<0.01,{ }^{* * *} p<0.001$ vs WT, Bonferroni post hoc; $n=3-7 /$ group. Scale bars: $(\boldsymbol{b}-\boldsymbol{d}, \boldsymbol{I}), 20 \mu \mathrm{m}$.

Table 1. Classification criteria for SGZ cells in stages of neurogenesis

\begin{tabular}{llc}
\hline Cell type & Morphology & Ki67 immunoreactivity \\
\hline NSC & Triangular soma, single projection through GCL, tuft of very fine processes & Rarely positive \\
& terminating in inner molecular layer & Negative \\
TAP & Irregular soma, no process & Positive \\
Neuroblast & Irregular soma, no/small process & Positive \\
Immature neuron & Round soma, process extends through GCL & Negative \\
Neuron & Round soma, projections through GCL, full dendritic tree extending & Negative \\
& through entire molecular layer & Positive \\
\hline
\end{tabular}

affected in Notch1 iKO mice. However, we did find that the proportion of proliferating cells was decreased in Notch1 iKO mice (supplemental Fig. $1 j$, available at www.jneurosci.org as supplemental material). Consistent with decreased proliferation, we found fewer cells in the cell cycle in Notch1 iKO mice (Fig. 2j). Further, there was no expansion of Ki67+ cells in iKO mice, resulting in an earlier peak and decreased neurogenesis in Notch1 iKO mice (Fig. $2 k$ ). We determined that these differences in cell number were not due to increased apoptosis (Fig. $2 l$ ). Previous reports suggest that Notch1 also modulates dendritic morphology of adult-generated neurons (Breunig et al., 2007). While we saw no difference in the number of branches between genotypes (Fig. 3a), Sholl analysis revealed a smaller dendritic tree in
$\mathrm{YFP}+\mathrm{Ki67}-\mathrm{DCX}+$ immature neurons in Notch1 iKO mice (Fig. $3 b, c)$. Together, these data show that elimination of Notch1 from nestin-expressing cells and their progeny decreased the number of YFP + cells at all stages of neurogenesis without affecting cell fate, decreased the proportion of TAPs without changing cell death, and decreased the size of the dendritic tree of immature neurons in vivo.

In agreement with the decline in Type-1 NSCs and progenitors after eliminating Notch1 in vivo (Fig. 2), NSCs isolated from adult Notch1 iKO mice generated 70\% fewer secondary neurospheres in vitro compared with WT littermates (Fig. 4a). While neurospheres from WT mice could be continuously passaged, neurospheres from Notch1 iKO mice could not be continuously 
Table 2. Statistical results and numerical analysis

\begin{tabular}{|c|c|c|c|c|}
\hline Number of & Figure & Interaction & ANOVA statistics & $p$ value \\
\hline Total YFP + cells & $1 c$ & Genotype $\times$ time & $F_{(3,52)}=9.55$ & $p<0.0001$ \\
\hline YFP + Type-1 NSCs & $2 e$ & Genotype $\times$ time & $F_{(3,41)}=3.08$ & $p=0.04$ \\
\hline \multirow{2}{*}{ YFP + Ki67+DCX - cells } & \multirow[t]{2}{*}{$2 f$} & Genotype $\times$ time & $F_{(3,26)}^{(3,4)}=1.74$ & $p=\mathrm{ns}$ \\
\hline & & Genotype & $F_{(1,26)}=7.92$ & $p=0.009$ \\
\hline YFP + Ki67+DCX + cells & $2 g$ & Genotype $\times$ time & $F_{(3,28)}=4.79$ & $p=0.008$ \\
\hline YFP + Ki67-DCX+ cells & $2 h$ & Genotype $\times$ time & $F_{(3,26)}=6.29$ & $p=0.002$ \\
\hline YFP + neurons & $2 i$ & Genotype $\times$ time & $F_{(3,35)}^{(3,20)}=3.06$ & $p=0.04$ \\
\hline YFP+Ki67+ cells & $2 j$ & Genotype $\times$ time & $F_{(3,19)}^{(3,3)}=8.66$ & $p=0.0008$ \\
\hline $\mathrm{YFP}+\mathrm{DCX}+$ cells & $2 k$ & Genotype $\times$ time & $F_{(3,19)}=10.62$ & $p=0.0003$ \\
\hline Total AC3 + cells & 21 & Genotype $\times$ time & $F_{(3,31)}=1.07$ & $p=\mathrm{ns}$ \\
\hline YFP + GFAP + cells & $S-1 a$ & N/A, Student's $t$ test & - & $p=0.05$ \\
\hline YFP + Type-1 NSCs & $S-1 a$ & $\mathrm{~N} / \mathrm{A}$, Student's $t$ test & - & $p=0.01$ \\
\hline YFP + NeuN + cells & S-1d & N/A, Student's $t$ test & - & $p=0.04$ \\
\hline YFP+ neurons & S-1d & $\mathrm{N} / \mathrm{A}$, Student's $t$ test & - & $p=0.02$ \\
\hline$Y F P+D C X+$ dendrites per YFP + DCX + soma & $3 a$ & $\mathrm{~N} / \mathrm{A}$, Student's $t$ test & - & $p=\mathrm{ns}$ \\
\hline Intersections & $3 b$ & Genotype $\times$ radius & $F_{(43,1763)}=3.07$ & $p<0.0001$ \\
\hline Secondary neurospheres & $4 a$ & N/A, Student's $t$ test & - & $p=0.0009$ \\
\hline Wheel revolutions & $5 a$ & Genotype $\times$ day & $F_{(29,290)}=1.13$ & $p=\mathrm{ns}$ \\
\hline Total YFP + cells - WT & $S-5 a$ & Housing condition & $F_{(2,13)}=4.14$ & $p=0.04$ \\
\hline Total YFP+ cells - iKO & $S-5 b$ & Housing condition & $F_{(2,14)}=11.52$ & $p=0.02$ \\
\hline Total YFP + cells & $5 c$ & Genotype $\times$ running & $F_{(1,27)}=4.41$ & $p=0.045$ \\
\hline YFP + Type-1 NSCs & $6 a$ & Genotype $\times$ running & $F_{(1,26)}^{(1,27)}=0.34$ & $p=\mathrm{ns}$ \\
\hline YFP + Ki67+DCX - cells & $6 b$ & Genotype $\times$ running & $F_{(1,19)}=0.04$ & $p=\mathrm{ns}$ \\
\hline YFP + Ki67+DCX + cells & $6 c$ & Genotype $\times$ running & $F_{(1,20)}=5.90$ & $p=0.02$ \\
\hline YFP + Ki67-DCX + cells & $6 d$ & Genotype $\times$ running & $F_{(1,19)}^{(1,2)}=0.60$ & $p=\mathrm{ns}$ \\
\hline & & Running & $F_{(1,19)}=23.87$ & $p<0.0001$ \\
\hline YFP+Ki67+ cells & $6 e$ & Genotype $\times$ running & $F_{(1,21)}=7.59$ & $p=0.012$ \\
\hline $\mathrm{YFP}+\mathrm{DCX}+$ cells & $6 f$ & Genotype $\times$ running & $F_{(1,21)}=1.73$ & $p=\mathrm{ns}$ \\
\hline & & Running & $F_{(1,21)}=21.15$ & $p=0.0002$ \\
\hline
\end{tabular}

N/A, Not applicable; S-, supplemental figures (available at www.jneurosci.org as supplemental material).

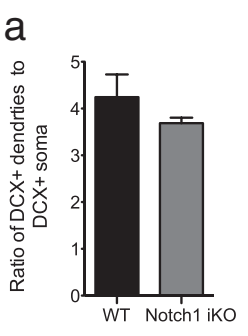

b

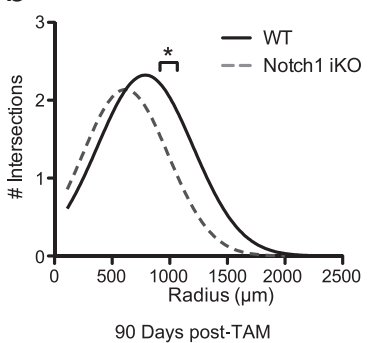

C

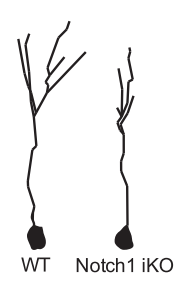

90 Days post-TAM

Figure 3. Dendritic morphology is decreased in Notch 1 iKO mice. $\boldsymbol{a}$, The number of dendrites per cell body in YFP $+D C X+$ cells in the SGZ did not differ between the two genotypes at $90 \mathrm{~d}$ post-TAM. $\boldsymbol{b}$, Sholl analysis of YFP $+D C X+$ cells revealed significantly fewer dendritic intersections in Notch1 iKO mice, specifically at a radius range of 960-1060 $\mu \mathrm{m}$. c, Representative $\mathrm{YFP}+\mathrm{DCX}+$ neuron tracings. ${ }^{*} p<0.05$ vs WT, Bonferroni post hoc; $n=3-4 /$ group.

propagated (Fig. 4b). Therefore Notch1 is necessary for the expansion and self-renewal of nestin-expressing cells in the adult SGZ in vivo and in vitro.

\section{Running rescues YFP+ neurogenesis but not Type-1 NSCs or TAPs in Notch1 iKO mice}

Given that physical activity potently stimulates hippocampal neurogenesis (van Praag et al., 1999b; Naylor et al., 2008) and specifically increases proliferation of TAPs and neuroblasts (Fabel and Kempermann, 2008), we explored whether physical activity could rescue the deficits in YFP + cell number in Notch1 iKO mice. Thirty days post-TAM, WT and Notch1 iKO littermates were given access to a running wheel for $30 \mathrm{~d}$ (Fig. $5 a$ ). WT and Notch1 iKO mice ran similar distances and had similar running patterns (Fig. 5a). There were no statistical differences
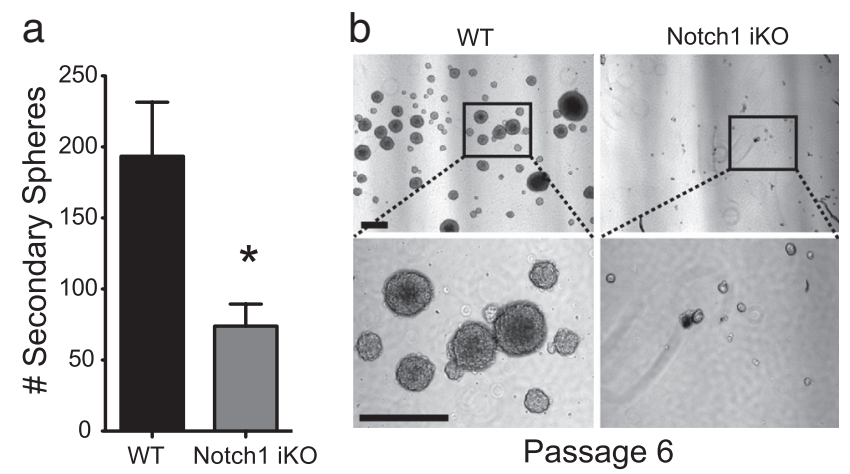

Figure 4. Elimination of Notch1 from nestin-expressing Type-1 NSCs in vivo decreases neurosphere formation in vitro. $\boldsymbol{a}$, Number of secondary spheres formed from cells isolated $40 \mathrm{~d}$ post-TAM from the subventricular zone of WT and Notch1 iKO mice. $\boldsymbol{b}$, Representative photomicrographs of passage 6 neurospheres from WT and Notch1 iKO mice. Scale bars, $100 \mu \mathrm{m}$. ${ }^{*} p<$ $0.05, t$ test; $n=3-4$ replicates per group.

found between mice single-housed with a locked running wheel and naive, group-housed mice, so data from these nonrunner groups were combined and compared with the running group. For example, total YFP + cells in naive WT mice were not significantly different from WT mice single-housed with a locked wheel (supplemental Fig. $2 a, b$, available at www.jneurosci.org as supplemental material). While physical activity increased total YFP + cell number (Fig. $5 b, c$ ), it failed to rescue either Type- 1 NSCs or TAPs in Notch1 iKO mice (Fig. $6 a, b$ ). However, physical activity restored proliferation (Fig. $6 e$ ) and neurogenesis (Fig. $6 f$ ), and specifically rescued YFP + neuroblast and immature neuron cell numbers (Fig. $6 c$, $d$; supplemental Fig. 2, available at 


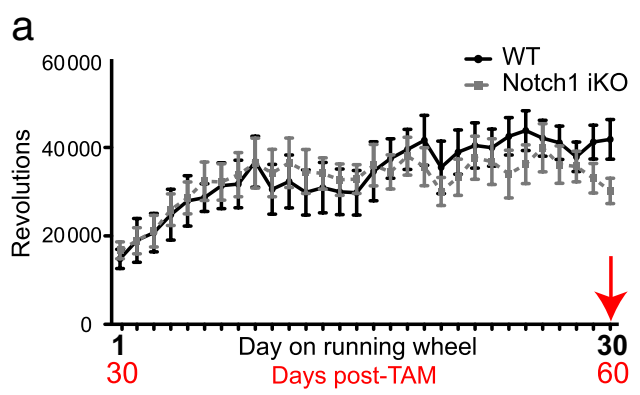

b
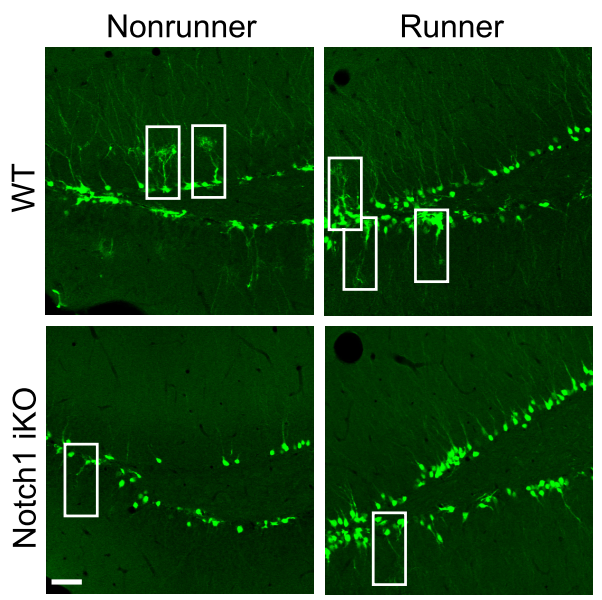

C

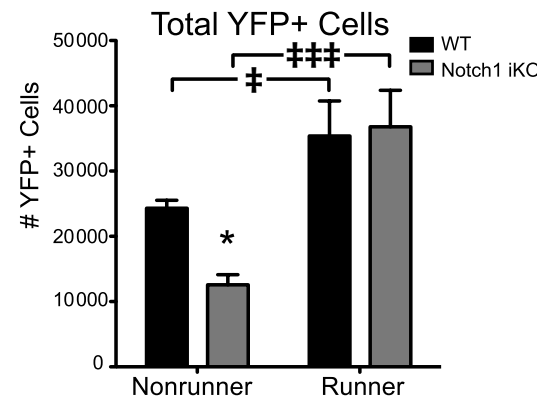

Figure 5. Physical activity rescues total YFP + cell number in Notch1 iKO runner mice. $\boldsymbol{a}$, Beginning $30 \mathrm{~d}$ post-TAM, animals were given free access to a running wheel for $30 \mathrm{~d}$. WT and Notch1 iKO mice did not differ in the amount they ran in any given day. $\boldsymbol{b}$, YFP + SGZ cells in WT and Notch1 iKO nonrunners and runners; white boxes, Type-1 NSCS. c, Total YFP+ SGZ cells. Scale bar, $20 \mu \mathrm{m} .{ }^{*} p<0.05$ vs WT and ${ }^{\ddagger} p<0.05,{ }^{\ddagger \neq \ddagger} p<0.001$ vs nonrunner, Bonferroni post hoc; $n=4-11 /$ group.

www.jneurosci.org as supplemental material). These data show that unlike neuroblasts, Type-1 NSCs and TAPs uniquely require Notch1 to regulate their number in the adult SGZ.

\section{Discussion}

We provide several lines of evidence that Notch 1 signaling in nestin-expressing cells maintains the size of the undifferentiated pool of stem and progenitor cells in the adult SGZ under basal conditions. We find fewer YFP + SGZ cell numbers in our inducible transgenic mice in which Notch1 was eliminated from nestin-expressing cells. Although the number of cells at all stages of neurogenesis is reduced in $\mathrm{iKO}$ mice, the undifferentiated Type-1 NSC and TAP populations seem particularly vulnerable to ablation of Notch1 signaling. There is a dramatic loss of YFPlabeled Type-1 NSCs over time, paralleling a simultaneous significant loss of TAPs. It is unlikely that decreases in cell number are the result of cell death, as we found no evidence of increased apoptosis. Instead, we interpret the decrease in NSCs and TAPs in
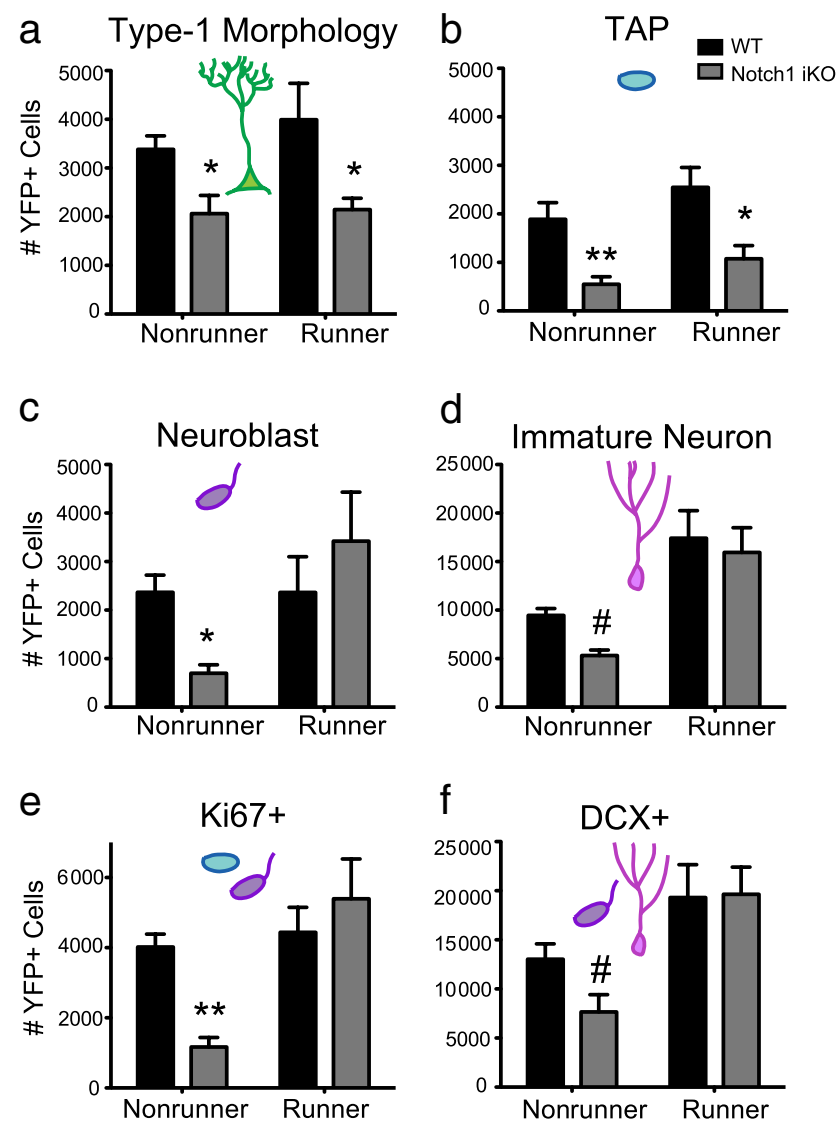

Figure 6. Physical activity rescues YFP + neurogenesis but not YFP + Type-1 NSCs or TAPs in Notch1 iKO mice. $\boldsymbol{a}$, Thirty days of running did not affect the number of YFP + Type-1 NSCs. $\boldsymbol{b}$, Thirty days of running did not affect the number of TAPs (YFP + Ki67 +DCX - cells). c, Running rescued the number of neuroblasts (YFP + Ki67+DCX+ cells) in Notch1 iKO mice. $d$, Running rescued the number of immature neurons (YFP + Ki67 - DCX+ cells) in iKO mice.e, Thirty days of running was sufficient to normalize the number of proliferating $(\mathrm{Ki67}+)$ YFP + cells in Notch1 iKO mice to WT levels. $\boldsymbol{f}$, The number of $D C X+Y F P+$ cells was increased in both WT and iKO mice after running. ${ }^{\#} p<0.1,{ }^{*} p<0.05,{ }^{* *} p<0.01$ vs WT, Bonferroni post hoc; $n=$ 3-8/group.

Notch1 iKO mice as a failure to self-renew and expand the YFP+ population. Ultimately, precocious cell cycle exit of NSCs and TAPs leads to fewer neuroblasts and immature neurons, culminating in 50\% fewer YFP+ neurons without Notch1. In addition to these robust in vivo findings, progenitor cells from adult Notch1 iKO mice are impaired in their ability to self-renew and proliferate in the neurosphere assay in vitro, further emphasizing the importance of Notch1 in regulating and maintaining the reservoir of stem-like cells in the adult.

Our time course studies notably extend data from previous reports that suggest Notch1 regulates cell cycle entry and exit of neural stem and progenitor cells (Guentchev and McKay, 2006; Breunig et al., 2007; Guo et al., 2009; Wang et al., 2009). Based on these studies and the anti-differentiation nature of Notch signaling (Yoon and Gaiano, 2005), we hypothesized that eliminating Notch1 from nestin-expressing cells would result in proportionally more YFP+ neurons at the cost of stem and progenitor cells. Surprisingly, WT and Notch1 iKO mice are indistinguishable at early times post-TAM ( $\leq 30 \mathrm{~d})$, and it is not until later times ( $\geq 60$ d) that we find significantly fewer Type-1 NSCs and TAPs and fewer YFP + cells in the cell cycle $(\mathrm{Ki} 67+)$ in Notch1 iKO mice. We interpret these findings as decreased stem cell renewal and increased cell cycle exit, respectively, although shorter and longer 

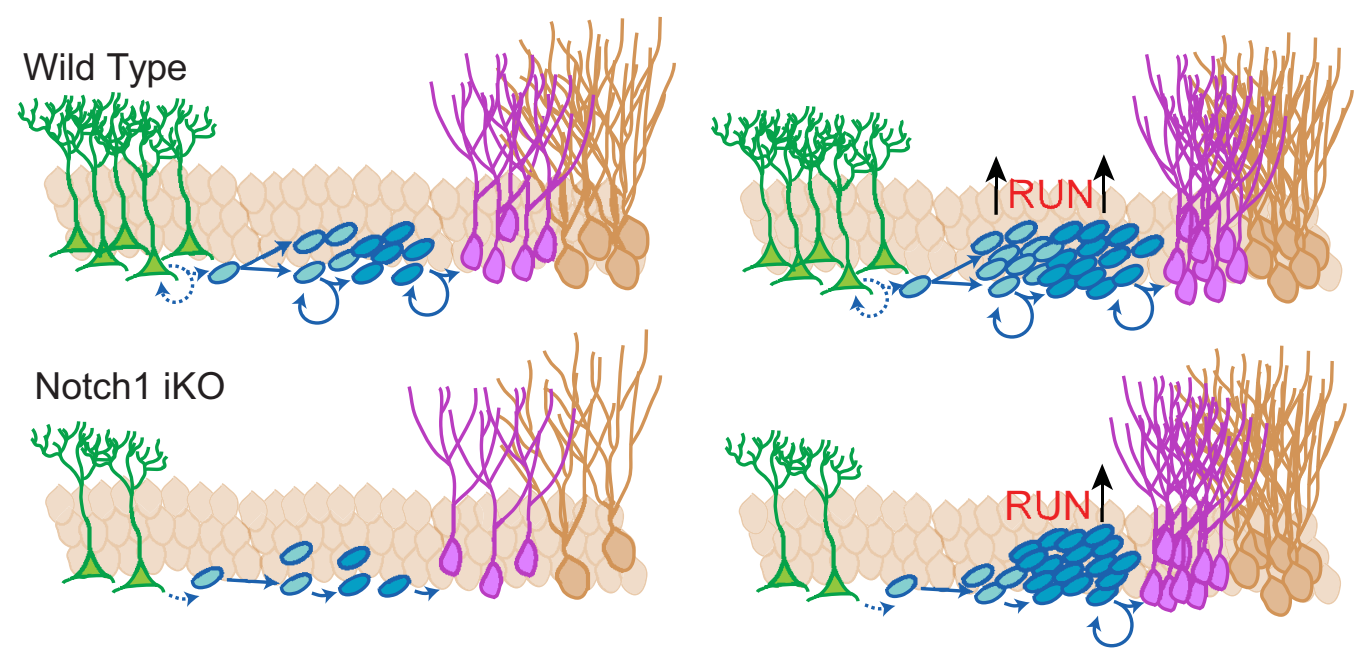

Figure 7. Proposed model of Notch1 in regulating adult neurogenesis under basal conditions and after physical activity. Without Notch1, self-renewal and expansion of nestin-expressing cells is disrupted and the net number of adult-generated dentate gyrus neurons is decreased. Physical activity increases adult-generated neurons in WT and Notch1 iKO mice by increasing neuroblast proliferation. However, physical activity does not rescue Type-1 NSC or TAP number in Notch1 iKO mice.

time points might reveal whether the absence of Notch 1 signaling forces Type-1 NSCs to enter the cell cycle and become TAPs (Imayoshi et al., 2010). However, in contrast to Bruenig and colleagues and our own hypothesis, we never observe an increased proportion of YFP + cells that were DCX + in Notch1 iKO mice. Further, we did not observe an increase in neurons at the expense of NSCs; instead, the total number of YFP + neurons generated in Notch1 iKO mice was reduced but proportional to YFP+ neurons in WT mice. Together, these data suggest that following inducible removal of Notch1 from nestin-expressing cells, Type-1 NSCs and TAPs exit the cell cycle, thereby precluding progenitor cell expansion and decreasing the number of YFP+ progenitors available to mature into new neurons. Importantly, our data do not demonstrate a role for Notch1 in regulating the fate of the progeny of nestin-expressing cells.

The disparities between Breunig and colleagues and our own observations likely reflect differences in the stem cell population that was recombined (GFAP vs nestin), especially given the context-dependent nature of Notch signaling (Poellinger and Lendahl, 2008; Cau and Blader, 2009). Perhaps in GFAPexpressing neural stem cells Notch1 regulates both proliferation and neuronal fate, while in nestin-expressing stem cells-where neuronal fate may already be determined (Lagace et al., 2007; Steiner et al., 2008)—Notch1 may regulate only proliferation. Ultimately, both our data and the data from Breunig and colleagues support that Notch1 is required for the maintenance of a pool of proliferating undifferentiated cells in the adult SGZ. These results underscore the power of the inducible transgenic approach to dissect the role of a multipurpose protein, like Notch1, in its contribution to a dynamic, complex, and contextdependent physiological process like neurogenesis.

Based on the observation that proliferation was decreased in Notch1 iKO mice, we hypothesized that the deficits in progenitor cells might be rescued by exercise, which is among the most potent inducers of neurogenesis in the adult SGZ (van Praag et al., 1999a; van Praag, 2008). Running increases the proliferative activity and number of TAPs and neuroblasts, with either modest or no detectable changes in the proliferative activity or number of Type-1 NSCs (Kronenberg et al., 2003; Suh et al., 2007; Lugert et al., 2010). Surprisingly, we find that running increases neuroblast proliferation and rescues neurogenesis in Notch1 iKO mice, de- spite persistent deficits in both the Type-1 NSC and TAP pools. Therefore, it seems that while Notch1 is critical for maintenance of undifferentiated progenitor cells, Notch 1 deficits alone cannot inhibit physical activity-dependent neurogenesis (Fig. 7). One interpretation is that Type-1 NSCs are not necessary for runninginduced proliferation, consistent with the above-mentioned reports that NSCs proliferate modestly, if at all, in response to running. However, nestin + TAPs, which ordinarily respond to running, may require Notch 1 signaling to remain in the cell cycle, in contrast to recent findings (Lugert et al., 2010). Alternatively, the remaining YFP+ neuroblasts lacking Notch1 may be hyperresponsive to running and proliferate more to overcome deficits in progenitor cells. Perhaps neurotrophic factors and components of the neurogenic niche that are necessary for exerciseinduced neurogenesis, such as BDNF, VEGF, $\beta$-endorphin and/or endocannabinoids, are sufficient to increase neuroblast proliferation in the absence of Notch1 signaling (Fabel et al., 2003; Kitamura et al., 2003; Bjørnebekk et al., 2005; Koehl et al., 2008; Hill et al., 2010; Lafenêtre et al., 2010). It is also possible that alternate pathways (e.g., mediated by GSK3, Shh, Wnt, or Sox2) can compensate for the lack of Notch1 in DCX + differentiating cells but not in undifferentiated Type-1 NSCs or TAPs (Hurlbut et al., 2007; Annenkov, 2009; Favaro et al., 2009; D. Chichung Lie, personal communication). Regardless, the observed normalization of neuroblast proliferation and number of YFP + neurons highlights the complex interplay between stem and progenitor cells, the neurogenic niche, and environmental stimuli, and encourages mechanistic studies into how Notch1 regulates adult neurogenesis in general and Type-1 NSCs in particular.

The data presented here have several implications. Particularly intriguing is our observation that running can bypass a genetic lesion with key cellular consequences (gradual depletion of neural progenitors) and still normalize adult neurogenesis. These data highlight the possibility of physical activity-based therapy in neurogenesis-related memory and mood disorders, and encourage analysis of synaptic plasticity and behavior in our mutants. Further, our demonstration of a critical role for intact Notch1 signaling in NSC maintenance urges caution in the clinical use of gamma-secretase inhibitors (GSI) for the treatment of Alzheimer's and other diseases. Activation of Notch1 requires gammasecretase cleavage, therefore GSI also inhibit Notch1 activity 
(Geling et al., 2002) and SGZ progenitor proliferation (Breunig et al., 2007). Our data suggest that the resulting inhibition of Notch1 activity could result in decreased hippocampal neurogenesis and eventual depletion of hippocampal NSCs. Given that Alzheimer's disease models show decreased hippocampal neurogenesis (Donovan et al., 2006; Zhao et al., 2008; Lazarov and Marr, 2010), our results suggest long-term treatment with broadspectrum GSI might exacerbate Alzheimer's disease progression. While more work is needed to evaluate the long-term effects of GSIs on NSC maintenance, the inducible model presented here will be useful in elucidating the underlying mechanisms of Notch signaling in the adult SGZ and in exploring how therapeutic targeting may offset the decrease in neurogenesis relevant to memory, mood disorders, and neurodegenerative diseases.

\section{References}

Androutsellis-Theotokis A, Leker RR, Soldner F, Hoeppner DJ, Ravin R, Poser SW, Rueger MA, Bae SK, Kittappa R, McKay RD (2006) Notch signalling regulates stem cell numbers in vitro and in vivo. Nature 442:823-826.

Annenkov A (2009) The insulin-like growth factor (IGF) receptor type 1 (IGF1R) as an essential component of the signalling network regulating neurogenesis. Mol Neurobiol 40:195-215.

Artavanis-Tsakonas S, Rand MD, Lake RJ (1999) Notch signaling: cell fate control and signal integration in development. Science 284:770-776.

Basak O, Taylor V (2009) Stem cells of the adult mammalian brain and their niche. Cell Mol Life Sci 66:1057-1072.

Bednarczyk MR, Aumont A, Décary S, Bergeron R, Fernandes KJ (2009) Prolonged voluntary wheel-running stimulates neural precursors in the hippocampus and forebrain of adult CD1 mice. Hippocampus 19:913-927.

Bjørnebekk A, Mathé AA, Brené S (2005) The antidepressant effect of running is associated with increased hippocampal cell proliferation. Int J Neuropsychopharmacol 8:357-368.

Breunig JJ, Silbereis J, Vaccarino FM, Sestan N, Rakic P (2007) Notch regulates cell fate and dendrite morphology of newborn neurons in the postnatal dentate gyrus. Proc Natl Acad Sci U S A 104:20558-20563.

Brewer GJ, Torricelli JR (2007) Isolation and culture of adult neurons and neurospheres. Nat Protoc 2:1490-1498.

Carlén M, Meletis K, Göritz C, Darsalia V, Evergren E, Tanigaki K, Amendola M, Barnabé-Heider F, Yeung MS, Naldini L, Honjo T, Kokaia Z, Shupliakov O, Cassidy RM, Lindvall O, Frisén J (2009) Forebrain ependymal cells are Notch-dependent and generate neuroblasts and astrocytes after stroke. Nat Neurosci 12:259-267.

Cau E, Blader P (2009) Notch activity in the nervous system: to switch or not switch? Neural Dev 4:36.

Corbin JG, Gaiano N, Juliano SL, Poluch S, Stancik E, Haydar TF (2008) Regulation of neural progenitor cell development in the nervous system. J Neurochem 106:2272-2287.

Dahlhaus M, Hermans JM, Van Woerden LH, Saiepour MH, Nakazawa K, Mansvelder HD, Heimel JA, Levelt CN (2008) Notch1 signaling in pyramidal neurons regulates synaptic connectivity and experiencedependent modifications of acuity in the visual cortex. J Neurosci 28:10794-10802.

Doetsch F, Hen R (2005) Young and excitable: the function of new neurons in the adult mammalian brain. Curr Opin Neurobiol 15:121-128.

Donovan MH, Yazdani U, Norris RD, Games D, German DC, Eisch AJ (2006) Decreased adult hippocampal neurogenesis in the PDAPP mouse model of Alzheimer's disease. J Comp Neurol 495:70-83.

Donovan MH, Yamaguchi M, Eisch AJ (2008) Dynamic expression of TrkB receptor protein on proliferating and maturing cells in the adult mouse dentate gyrus. Hippocampus 18:435-439.

Duan X, Kang E, Liu CY, Ming GL, Song H (2008) Development of neural stem cell in the adult brain. Curr Opin Neurobiol 18:108-115.

Eisch AJ, Cameron HA, Encinas JM, Meltzer LA, Ming GL, OverstreetWadiche LS (2008) Adult neurogenesis, mental health, and mental illness: hope or hype? J Neurosci 28:11785-11791.

Fabel K, Kempermann G (2008) Physical activity and the regulation of neurogenesis in the adult and aging brain. Neuromol Med 10:59-66.

Fabel K, Tam B, Kaufer D, Baiker A, Simmons N, Kuo CJ, Palmer TD (2003)
VEGF is necessary for exercise-induced adult hippocampal neurogenesis. Eur J Neurosci 18:2803-2812.

Favaro R, Valotta M, Ferri AL, Latorre E, Mariani J, Giachino C, Lancini C, Tosetti V, Ottolenghi S, Taylor V, Nicolis SK (2009) Hippocampal development and neural stem cell maintenance require Sox2-dependent regulation of Shh. Nat Neurosci 10:1248-1256.

Geling A, Steiner H, Willem M, Bally-Cuif L, Haass C (2002) A gammasecretase inhibitor blocks Notch signaling in vivo and causes a severe neurogenic phenotype in zebrafish. EMBO Rep 3:688-694.

Guentchev M, McKay RD (2006) Notch controls proliferation and differentiation of stem cells in a dose-dependent manner. Eur J Neurosci 23:2289-2296.

Guo D, Ye J, Dai J, Li L, Chen F, Ma D, Ji C (2009) Notch-1 regulates Akt signaling pathway and the expression of cell cycle regulatory proteins cyclin D1, CDK2 and p21 in T-ALL cell lines. Leuk Res 33:678-685.

Hill MN, Titterness AK, Morrish AC, Carrier EJ, Lee TT, Gil-Mohapel J, Gorzalka BB, Hillard CJ, Christie BR (2010) Endogenous cannabinoid signaling is required for voluntary exercise-induced enhancement of progenitor cell proliferation in the hippocampus. Hippocampus 20:513-523.

Hurlbut GD, Kankel MW, Lake RJ, Artavanis-Tsakonas S (2007) Crossing paths with Notch in the hyper-network. Curr Opin Cell Biol 19:166-175.

Imayoshi I, Ohtsuka T, Metzger D, Chambon P, Kageyama R (2006) Temporal regulation of Cre recombinase activity in neural stem cells. Genesis 44:233-238.

Imayoshi I, Sakamoto M, Ohtsuka T, Takao K, Miyakawa T, Yamaguchi M, Mori K, Ikeda T, Itohara S, Kageyama R (2008) Roles of continuous neurogenesis in the structural and functional integrity of the adult forebrain. Nat Neurosci 11:1153-1161.

Imayoshi I, Sakamoto M, Yamaguchi M, Mori K, Kageyama R (2010) Essential roles of Notch signaling in maintenance of neural stem cells in developing and adult brains. J Neurosci 30:3489-3498.

Johnson MA, Ables JL, Eisch AJ (2009) Cell-intrinsic signals that regulate adult neurogenesis in vivo: insights from inducible approaches. BMB Rep 42:245-259.

Kempermann G, Jessberger S, Steiner B, Kronenberg G (2004) Milestones of neuronal development in the adult hippocampus. Trends Neurosci 27:447-452.

Kempermann G, Chesler EJ, Lu L, Williams RW, Gage FH (2006) Natural variation and genetic covariance in adult hippocampal neurogenesis. Proc Natl Acad Sci U S A 103:780-785.

Kitamura T, Mishina M, Sugiyama H (2003) Enhancement of neurogenesis by running wheel exercises is suppressed in mice lacking NMDA receptor epsilon 1 subunit. Neurosci Res 47:55-63.

Koehl M, Meerlo P, Gonzales D, Rontal A, Turek FW, Abrous DN (2008) Exercise-induced promotion of hippocampal cell proliferation requires beta-endorphin. FASEB J 22:2253-2262.

Kronenberg G, Reuter K, Steiner B, Brandt MD, Jessberger S, Yamaguchi M, Kempermann G (2003) Subpopulations of proliferating cells of the adult hippocampus respond differently to physiologic neurogenic stimuli. J Comp Neurol 467:455-463.

Lafenêtre P, Leske O, Ma-Högemeie Z, Haghikia A, Bichler Z, Wahle P, Heumann R (2010) Exercise can rescue recognition memory impairment in a model with reduced adult hippocampal neurogenesis. Front Behav Neurosci 3:34.

Lagace DC, Whitman MC, Noonan MA, Ables JL, DeCarolis NA, Arguello AA, Donovan MH, Fischer SJ, Farnbauch LA, Beech RD, DiLeone RJ, Greer CA, Mandyam CD, Eisch AJ (2007) Dynamic contribution of nestin-expressing stem cells to adult neurogenesis. J Neurosci 27:12623-12629.

Lagace DC, Benavides DR, Kansy JW, Mapelli M, Greengard P, Bibb JA, Eisch AJ (2008) Cdk5 is essential for adult hippocampal neurogenesis. Proc Natl Acad Sci U S A 105:18567-18571.

Lagace DC, Donovan MH, DeCarolis NA, Farnbauch LA, Malhotra S, Berton O, Nestler EJ, Krishnan V, Eisch AJ (2010) Adult hippocampal neurogenesis is functionally important for stress-induced social avoidance. Proc Natl Acad Sci U S A 107:4436-4441.

Lazarov O, Marr RA (2010) Neurogenesis and Alzheimer's disease: at the crossroads. Exp Neurol 223:267-281.

Lugert S, Basak O, Knuckles P, Haussler U, Fabel K, Götz M, Haas CA, Kempermann G, Taylor V, Giachino C (2010) Quiescent and active hippocampal neural stem cells with distinct morphologies respond selec- 
tively to physiological and pathological stimuli and aging. Cell Stem Cell 6:445-456.

Mandyam CD, Norris RD, Eisch AJ (2004) Chronic morphine induces premature mitosis of proliferating cells in the adult mouse subgranular zone. J Neurosci Res 76:783-794.

Ming GL, Song H (2005) Adult neurogenesis in the mammalian central nervous system. Annu Rev Neurosci 28:223-250.

Naylor AS, Bull C, Nilsson MK, Zhu C, Björk-Eriksson T, Eriksson PS, Blomgren K, Kuhn HG (2008) Voluntary running rescues adult hippocampal neurogenesis after irradiation of the young mouse brain. Proc Natl Acad Sci U S A 105:14632-14637.

Pietropaolo S, Sun Y, Li R, Brana C, Feldon J, Yee BK (2008) The impact of voluntary exercise on mental health in rodents: a neuroplasticity perspective. Behav Brain Res 192:42-60.

Poellinger L, Lendahl U (2008) Modulating Notch signaling by pathwayintrinsic and pathway-extrinsic mechanisms. Curr Opin Genet Dev 18:449-454.

Radtke F, Wilson A, Stark G, Bauer M, van Meerwijk J, MacDonald HR, Aguet M (1999) Deficient $T$ cell fate specification in mice with an induced inactivation of Notch1. Immunity 10:547-558.

Radtke F, Schweisguth F, Pear W (2005) The Notch 'gospel'. EMBO Rep 6:1120-1125.
Steiner B, Zurborg S, Hörster H, Fabel K, Kempermann G (2008) Differential $24 \mathrm{~h}$ responsiveness of Proxl-expressing precursor cells in adult hippocampal neurogenesis to physical activity, environmental enrichment, and kainic acid-induced seizures. Neuroscience 154:521-529.

Suh H, Consiglio A, Ray J, Sawai T, D’Amour KA, Gage FH (2007) In vivo fate analysis reveals the multipotent and self-renewal capacities of Sox $2+$ neural stem cells in the adult hippocampus. Cell Stem Cell 1:515-528.

van Praag H (2008) Neurogenesis and exercise: past and future directions. Neuromolecular Med 10:128-140.

van Praag H, Kempermann G, Gage FH (1999a) Running increases cell proliferation and neurogenesis in the adult mouse dentate gyrus. Nat Neurosci 2:266-270.

van Praag H, Christie BR, Sejnowski TJ, Gage FH (1999b) Running enhances neurogenesis, learning, and long-term potentiation in mice. Proc Natl Acad Sci U S A 96:13427-13431.

Wang X, Mao X, Xie L, Greenberg DA, Jin K (2009) Involvement of Notch1 signaling in neurogenesis in the subventricular zone of normal and ischemic rat brain in vivo. J Cereb Blood Flow Metab 29:1644-1654.

Yoon K, Gaiano N (2005) Notch signaling in the mammalian central nervous system: insights from mouse mutants. Nat Neurosci 8:709-715.

Zhao C, Deng W, Gage FH (2008) Mechanisms and functional implications of adult neurogenesis. Cell 132:645-660. 